\title{
Capsaicin causes inactivation and degradation of the androgen receptor by inducing the restoration of miR-449a in prostate cancer
}

\author{
LONG ZHENG, JIAQI CHEN, ZHENKUN MA, WEI LIU, FEI YANG, ZHAO YANG, \\ KE WANG, XINYANG WANG, DALIN HE and LEI LI \\ Department of Urology, The First Affiliated Hospital of Xi'an Jiaotong University, Xi'an 710061, P.R. China
}

Received April 16, 2015; Accepted May 27, 2015

DOI: $10.3892 /$ or.2015.4055

\begin{abstract}
Capsaicin, a novel antitumor agent extracted from chili peppers, has been proven to induce growth inhibition in various types of cancer including prostate cancer. However, the detailed mechanisms remain largely undiscovered. In the present study, we explored the regulation of the androgen receptor (AR) by capsaicin and further researched the mechanisms of their interaction in AR-positive prostate cancer cells. In the present study, cell viability was assessed by MTT assay. Cell cycle distribution was determined using flow cytometry. Expression levels of cyclin D1, miR-449a, AR and prostate-specific antigen (PSA) were assessed by quantitative real-time polymerase chain reaction or western blot analysis. To further confirm the relationship among miR-449a, AR and prostate cancer proliferation, miR-449a was overexpressed by a lentivirus in prostate cancer cells. We discovered that capsaicin prevented tumor proliferation and cell cycle progression through inactivation and degradation of AR. We also found that restoration of miR-449a induced by capsaicin treatment resulted in the inhibition of AR signaling. Finally, we demonstrated that increased expression of miR449a sensitized prostate cancer to capsaicin treatment. Finally, our experimental results indicated that capsaicin negatively modulates the activity of AR at the mRNA and protein levels by restoring miR-449a profiling in prostate cancer. In addition,
\end{abstract}

Correspondence to: Professor Lei Li or Professor Dalin He, Department of Urology, The First Affiliated Hospital of Xi'an Jiaotong University, 277 Yanta West Road, Xi'an 710061, P.R. China E-mail: 1ilydr@163.com

E-mail: dalinhexjtu@126.com

Abbreviations: AR, androgen receptor; PSA, prostate-specific antigen; CRPC, castration-resistant prostate cancer; miRNA, microRNAs; DMSO, dimethyl sulfoxide

Key words: capsaicin, androgen receptor, miR-449a, prostate cancer, growth inhibition increased expression of miR-449a may facilitate the sensitivity of prostate cancer to capsaicin treatment. Thus, capsaicin may be developed as a novel anti-AR drug for the therapy of prostate cancer.

\section{Introduction}

Prostate cancer (PCa), also known as carcinoma of the prostate, is the development of cancer in the prostate gland. The mortality of PCa is the second leading cause of cancer-related mortality in the United States (1). PCa grows slowly and cell proliferation depends on the androgen levels in the early stage. Conventional anti-androgen therapy can control the progression of the disease at this stage. Yet, the cancer becomes difficult to cure when it progresses into castration-resistant prostate cancer (CRPC) (2). Thus, patients who suffer from CRPC have an extremely poor prognosis. Thus, elucidating the mechanism of CRPC is critical to prevent PCa progression. The proliferation and survival of prostate cells depend on the essential hormone androgen and the androgen receptor (AR), which is the principal receptor responsible for mediating the physiological effects of androgens. The AR plays a critical role in the progression of androgen-sensitive to castrationresistant $\mathrm{PCa}$. PCa activity of the AR is augmented and may be activated by other stimuli or adaptive signaling pathways, during the progression to castration-resistant PCa $(3,4)$. Many drugs that are applied in the clinic may block the binding of androgens to ARs attenuating the activity of AR and inhibiting the proliferation of PCa cells (5). However, the AR may become more sensitive to androgens and may be activated by adaptive pathways as PCa becomes resistant to castration or anti-androgen treatment $(6,7)$. Therefore, development of new drugs that directly target the AR protein is urgently needed.

Capsaicin, a pungent spicy ingredient extracted from red peppers, has been recently demonstrated to induce growth inhibition in many types of tumors including PCa (8). Sánchez et al demonstrated that capsaicin enhanced apoptosis by induction of reactive oxygen species (ROS) generation, a decrease in the mitochondrial inner transmembrane potential and activation of caspase-3 in prostate cancer cells (9). However, the relationship between capsaicin and AR and the relevant mechanisms remain largely unknown. 
microRNAs (miRNAs) are a class of small non-coding RNAs (ncRNAs) that regulate gene expression by repressing translation and have been proven to be involved in the regulation of critical processes, such as proliferation, differentiation and apoptosis in various types of cancer (10). Among the miRNAs, miR-449a functions as an important tumor suppressor in many types of tumors by targeting different genes. In PCa, Noonan et al found that miR-449a caused cell cycle arrest by suppressing $\mathrm{Rb}$ phosphorylation (11) and by directly targeting HDAC1 (12). By regulating the activation of $\mathrm{Rb}$, miR-449a also induced growth arrest and senescence in an $\mathrm{Rb}$-dependent manner (11). Previous studies demonstrated that capsaicin may influence the expression of miRNAs or synergize with miRNAs to enhance its tumor-suppressive function $(13,14)$. However, whether capsaicin treatment regulates miR-449a expression and thereby changes the activation of downstream genes remains unknown. In the present study, we explored the function of capsaicin on miR-449a expression and further researched the downstream effects of miR-449a overexpression induced by capsaicin, aiming to elucidate capsaicin/miR-449a interaction and its influence on PCa.

\section{Materials and methods}

Reagents. Capsaicin (M2028) was purchased from Sigma-Aldrich (St. Louis, MO, USA) and was diluted into a $200 \mathrm{mmol} / 1$ stock solution with DMSO. Anti-AR rabbit polyclonal antibody (N20) and anti-glyceraldehyde-phosphate dehydrogenase (GAPDH) mouse monoclone antibody were purchased from Santa Cruz Biotechnology (Santa Cruz, CA, USA). Anti-cyclin D1 mouse monoclonal antibody was obtained from Proteintech (Chicago, IL, USA).

Cell culture. Human C4-2 and LNCaP cells were obtained from the American Type Culture Collection (ATCC; Rockville, MD, USA). The two cell lines were cultured at $37^{\circ} \mathrm{C}$ in humidified air containing $5 \%$ of $\mathrm{CO}_{2}$. Both cell lines were cultured in RPMI-1640 medium with $10 \%$ fetal bovine serum (FBS) (Gibco, Carlsbad, CA, USA) containing 1\% of penicillin-streptomycin.

Lentiviral infection. C4-2 and LNCaP cells were seeded in a $10-\mathrm{cm}$ dish and a lentivirus that overexpressed miR-449a was transfected into 293T cells. Forty-eight hours after transfection, viral supernatant fractions were collected and then infected into the C4-2 and LNCaP cells along with $10 \mu \mathrm{g} / \mathrm{ml}$ Polybrene. Twenty-four hours after infection, the medium was replaced with fresh medium.

Cell proliferation assay. Cell viability was analyzed by MTT assay. Cells $\left(8 \times 10^{3} /\right.$ well) were seeded in 96 -well culture plates and incubated overnight. Then, the cells were treated with capsaicin $(0,50,100,150$ and $200 \mu \mathrm{M})$ for 2 days. After being washed once, $0.5 \mathrm{mg} / \mathrm{ml}$ of MTT was added and incubation was carried out at $37^{\circ} \mathrm{C}$. Four hours later, the culture medium was removed carefully and dimethyl sulfoxide (DMSO) was added to solubilize the formazan crystals. Finally, the absorbance was measured at a wavelength of $490 \mathrm{~nm}$ using a microplate autoreader (Bio-Tek Instruments Inc., Winooski, VT, USA). Independent experiments were repeated in triplicate.
Flow cytometric analysis. Flow cytometric analysis was applied to evaluate the cell cycle progression and apoptosis. After the indicated capsaicin treatments for 2 days, the cells in each group were harvested and washed twice and then $70 \%$ ethanol was used to fix the cells at $-20^{\circ} \mathrm{C}$ for at least $24 \mathrm{~h}$. For the apoptosis assay, the cells were washed twice and stained with propidium iodide (PI) and Annexin V-FITC (BD Pharmingen, San Diego, CA, USA) at appropriate concentrations and time according to the manufacturer's protocol. For cell cycle detection, the cells were washed twice and incubated with $50 \mu \mathrm{g} /$ $\mathrm{ml} \mathrm{PI} \mathrm{and} 50 \mu \mathrm{g} / \mathrm{ml}$ RNase A at room temperature for $30 \mathrm{~min}$. Then, flow cytometry was performed using a FACSCalibur system with CELLQuest software version 3.3 (both from Becton Dickinson, San Jose, CA, USA), and the cell cycle distribution was calculated using ModFit LT software (version 3.0; Verity Software House, Topsham, ME, USA).

Total RNA isolation and reverse transcription. Total RNA for each group was extracted using Fast 200 kit (Feijie Biotechnology, Shanghai, China) and was reverse transcribed using PrimerScript ${ }^{\mathrm{TM}}$ RT Master Mix (Takara Biotechnology Co., Ltd., Dalian, China) according to the manufacturer's protocol. 5X PrimeScript RT Master Mix (2 $\mu \mathrm{l})$, RNase free- $\mathrm{dH}_{2} \mathrm{O}(7 \mu \mathrm{l})$ and total RNA $(1 \mu \mathrm{l})$ were mixed. Then, the protocol was followed: $37^{\circ} \mathrm{C}$ for $16 \mathrm{~min}$ and $85^{\circ} \mathrm{C}$ for $5 \mathrm{sec}$.

miRNA isolation and reverse transcription. miRNA in the capsaicin-treated groups of the C4-2 and LNCaP cells was extracted using TRIzol and quantified at an absorbance of $260 \mathrm{~nm}$. RNA (5000 ng) was reverse transcribed using PrimerScript ${ }^{\mathrm{TM}}$ RT Master Mix according to the manufacturer's protocol.

Quantitative real-time polymerase chain reaction ( $q P C R)$. qPCR was carried out using the Bio-Rad CFX96 ${ }^{\mathrm{TM}}$ real-time system (Bio-Rad, Hercules, CA, USA) and the SYBRR Premix Ex Taq ${ }^{\mathrm{TM}}$ II system (Takara). The SYBRR Premix Ex Taq II $(12.5 \mu \mathrm{l}), 1 \mu \mathrm{l}$ primer $(10 \mu \mathrm{M}), 2 \mu \mathrm{l}$ cDNA solution and $8.5 \mu \mathrm{l}$ Rnase-free water were mixed together, followed by the second stage of pre-degeneration at $95^{\circ} \mathrm{C}$ for $30 \mathrm{sec}$, one repeat and PCR reaction, $95^{\circ} \mathrm{C}$ for $5 \mathrm{sec}$ followed by $60^{\circ} \mathrm{C}$ for $30 \mathrm{sec}$, 40 repeats and the third stage of dissociation at $95^{\circ} \mathrm{C}$ for $15 \mathrm{sec}$ followed by $60^{\circ} \mathrm{C}$ for $30 \mathrm{sec}$ and at $95^{\circ} \mathrm{C}$ for $15 \mathrm{sec}$. The data were collected. GAPDH was used as the internal control. Primers used for amplification were as follows: AR sense, 5'-CCAGGGACCATGTTTTGCC-3' and AR antisense, 5'-CG AAGACGACAAGATGGACAA-3'; PSA sense, 5'-GTGTGT GGACCTCCATGTTATT-3' and PSA antisense, 5'-CCACTC ACCTTTCCCCTCAAG-3'. The primer for miR-449a was purchased from Takara.

Western blot analysis. After capsaicin treatment for $48 \mathrm{~h}$, proteins from the C4-2 and LNCaP cells were harvested with RIPA buffer [50 mM Tris (pH 8.0), $150 \mathrm{mM} \mathrm{NaCl}, 0.1 \%$ SDS, $1 \%$ NP-40 and $0.5 \%$ sodium deoxycholate] containing $1 \%$ cocktail and $1 \mathrm{mM}$ PMSF. The cellular lysates were centrifuged at $15,000 \mathrm{rpm}$ for $15 \mathrm{~min}$ at $4^{\circ} \mathrm{C}$, and the supernatants were harvested and mixed with loading buffer. The protein content was quantified using the Enhanced BCA Protein Assay kit (Beyotime Institute of Biotechnology, Jiangsu, China). 



Figure 1. Capsaicin inhibits prostate cancer cell proliferation. (A and C) MTT assay was used to detect the cell viability of C4-2 and LNCaP cells following treatment by capsaicin. (B and D) The bar graphs showing cell viability were constructed by GraphPad Prism software. DMSO, dimethyl sulfoxide; ${ }^{* *} \mathrm{P}<0.01$.

Then, the protein lysates were separated by SDS-PAGE on $10 \%$ gel and transferred to nitrocellulose membranes. After blocking in 5\% non-fat dry milk in TBS, the membranes were probed with specific primary antibodies overnight at $4^{\circ} \mathrm{C}$, washed three times with TBS Tween-20 and then incubated with HRP-conjugated secondary antibodies at room temperature for $1 \mathrm{~h}$. Then, the membranes were washed with TBS Tween-20 and incubated with secondary antibodies (supplied by Licor, Rockford, IL, USA) coupled to the primary antibody at room temperature in the dark for $1 \mathrm{~h}$, followed by washing as above in the dark, drying with neutral absorbent paper and scanning by Odyssey detection system (Licor). GAPDH was used as the loading control.

Statistical analysis. Data are expressed as the mean \pm SE from three independent experiments. Statistical analysis was carried out using a Student's t-test and SPSS 15.0 software (SPSS Inc., Chicago, IL, USA). P $<0.05$ was considered to indicate a statistically significant result.

\section{Results}

Capsaicin inhibits the proliferation of AR-positive PCa cells. Capsaicin has been proven as an antitumor drug due to its effect on promoting growth inhibition in various types of cancer. In order to verify whether capsaicin affects the proliferation of AR-positive PCa cells, we analyzed the effects of capsaicin on two PCa cell lines: C4-2 and LNCaP. The cell lines were grown in RPMI-1640 medium with 10\% FBS and treated with capsaicin at different concentrations for $48 \mathrm{~h}$. Cell viability was then examined by MTT assay. Capsaicin induced a dose-dependent inhibition of cell proliferation in both PCa cell lines. At the concentration of $100 \mu \mathrm{M}$, the cell viability of the C4-2 and LNCaP cells was 53 and $52 \%$, respectively (Fig. 1). The MTT assay showed that capsaicin inhibited cell proliferation in a dose-dependent manner. These results demonstrate that capsaicin inhibits the proliferation of PCa cells.

Capsaicin induces $G_{0} / G_{I}$ cell cycle arrest, but has little influence on apoptosis in AR-positive PCa cells. Anticancer drugs suppress cancer growth mainly through two modes: apoptosis and cell cycle arrest. According to previous studies, capsaicin induces apoptosis and cell cycle arrest leading to cancer growth suppression. Based on this, we further investigated the effects of capsaicin on apoptosis and cell cycle progression by flow cytometry. C4-2 and LNCaP cells, in a logarithmic growth phase, were treated with $100 \mu \mathrm{M}$ capsaicin for $48 \mathrm{~h}$. As shown in Fig. 2A and B, the percentage of C4-2 cell apoptosis was $12.29 \%$ following treatment with $100 \mu \mathrm{M}$ capsaicin for $48 \mathrm{~h}$, compared with the control group (22.49\%). Concerning the LNCaP cells, $100 \mu \mathrm{M}$ capsaicin treatment led to a $5.49 \%$ cell apoptosis, while the control group was $4.1 \%$. Thus, capsaicin did not lead to significant apoptosis in the C4-2 and LNCaP cells. Yet, a significant increase in the percentage of cells arrested in the $G_{0} / G_{1}$ phases in both cell lines was observed (Fig. 2C). In parallel, there was a reduction in the percentage of cells in the $S$ and $G_{2} / M$ phases. To confirm these data, western blot analysis was used to examine the expression of cyclin D1. Following treatment with capsaicin, cyclin D1 was obviously reduced both in the C4-2 and LNCaP cells (Fig. 2D). Collectively, these results demonstrated that capsaicin affected the expression of key proteins involved in the cell cycle and induced $\mathrm{G}_{0} / \mathrm{G}_{1}$ cell cycle arrest in the PCa cells. 
A
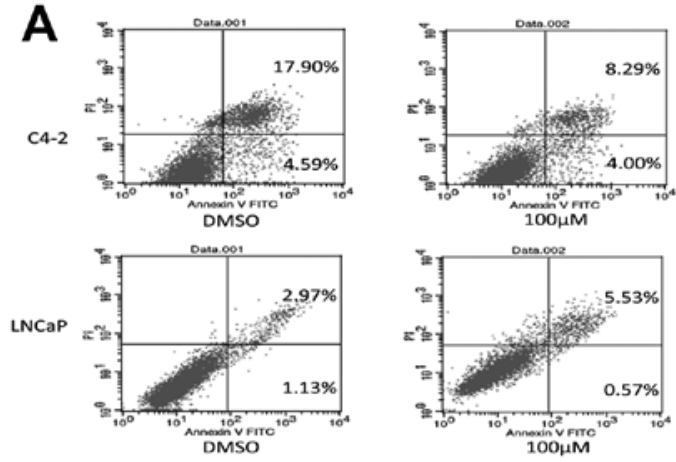

C



D

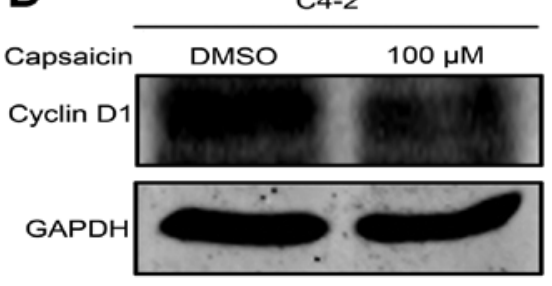

B
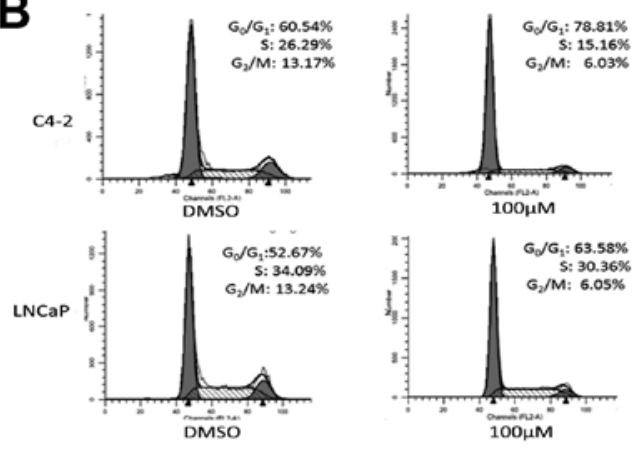

LNCaP
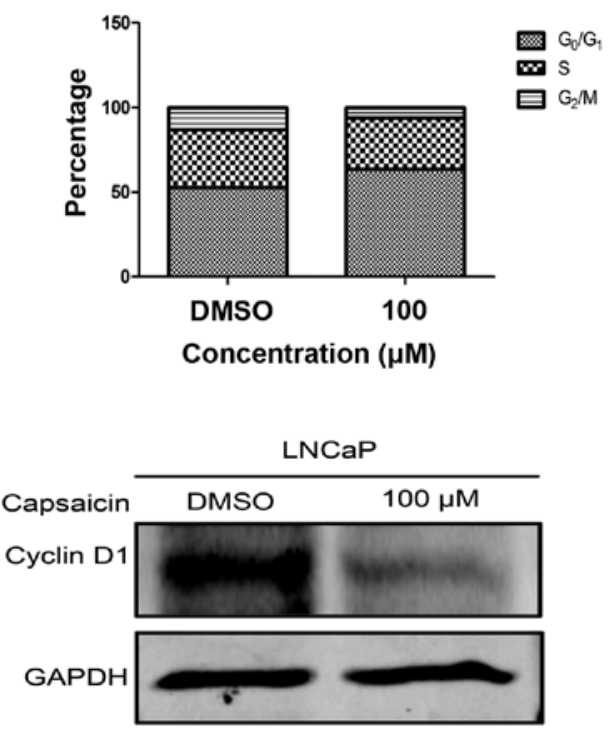

Figure 2. Capsaicin induces $\mathrm{G}_{0} / \mathrm{G}_{1}$ cell cycle arrest, but has little influence on the apoptosis of AR-positive prostate cancer cells. (A) Cell apoptosis and (B) cell cycle distribution of the prostate cancer cells were assessed by flow cytometry. (C) The bar graph showing the percentage of each phase of the cell cycle was constructed by GraphPad Prism software. (D) The level of cell cycle-regulating protein, cyclin D1, was detected by western blot analysis. DMSO, dimethyl sulfoxide.

Capsaicin inhibits $A R$ activation and decreases the $A R$ protein level. AR is the key factor of growth regulation and cell cycle progression in PCa. Jankovic et al reported that capsaicin delayed the PSA doubling time in a PCa patient who suffered biochemical failure after radiation (15). It appears that capsaicin may be associated with the inactivation of AR signaling. Aiming to explore the influence of capsaicin on AR function, we determined the expression of AR mRNA and protein in the control group and the capsaicin treatment groups. Compared with the control group, capsaicin treatment significantly decreased the AR mRNA levels in the C4-2 and LNCaP cells (Fig. 3A and C). In addition, the AR protein level was decreased in a dose-dependent manner following treatment with the indicated capsaicin concentrations in these two cell lines. In order to detect the AR function, we measured the expression of PSA, one of the target genes downstream of AR signaling, by real-time PCR. After capsaicin treatment for $48 \mathrm{~h}$, PSA expression was significantly reduced in the C4-2 and LNCaP cells, compared with the control group (Fig. 3B). Thus, capsaicin treatment may inhibit AR function and affect the expression of genes located downstream of AR signaling.

Restoration of miR-449a expression induced by capsaicin mediates a decrease in $A R$ protein and inactivation of $A R$ signaling. Previous research has confirmed that capsaicin regulates the expression of various miRNAs, such as miR-34a (16) and miR-520-5p (17). Firstly, we detected miR-449a expression in several AR-positive PCa cell lines. miR-449a was expressed in all selected AR-positive PCa cells (data not shown). Then, we detected the influence of capsaicin treatment on the expression of miR-449a. As shown in Fig. 4A, following capsaicin treatment, miR-449a expression was significantly elevated in both the C4-2 and LNCaP cells, compared with the control group. As previous studies have indicated, miR-449a is a potential negative regulator of AR. Next, we overexpressed miR-449a by a lentivirus to detect whether or not it functions with AR. Upon overexpression of miR-449a, the western blot results showed that the level of AR was downregulated (Fig. 4D), as compared with the level in the $\mathrm{NC}$ group in both cancer cell lines. In addition, expression of AR and PSA mRNA was inhibited (Fig. 4B and C). All data indicated that miR-449a mediated a decrease in AR following capsaicin treatment.

Overexpression of $m i R-449 a$ inhibits $P C a$ proliferation and enhances the antitumor effect of capsaicin. Aiming to further verify whether miR-449a has a growth inhibitory effect on PCa cells, we carried out MTT assay and cell cycle analysis. 
A



B


LNCaP


Figure 3. Capsaicin inhibits AR activation and decreases the AR protein level. (A) Expression of the AR mRNA levels in the control groups and capsaicin treatment groups, as detected by real-time PCR. (B) Expression of the PSA mRNA levels in the control groups and capsaicin treatment groups was detected by real-time PCR. (C) Western blot analysis was used to measure the influence of capsaicin treatment on AR protein levels. DMSO, dimethyl sulfoxide. ${ }^{*} \mathrm{P}<0.05$ and ${ }^{* *} \mathrm{P}<0.01$.

Based on the data, we determined that overexpression of miR-449a inhibited PCa growth in a time-dependent manner, when compared to the NC group (Fig. 5A). Considering that the cell cycle may play a role in growth inhibition, we detected cell cycle progression in the cells transfected with lenti-NC and lenti-miR449a. miR-449a expression induced $\mathrm{G}_{0} / \mathrm{G}_{1}$ phase arrest in both PCa cell lines (Fig. 5B). Notably, we found that miR-449a overexpression enhanced the antitumor effect of capsaicin treatment (Fig. 5C), indicating there may be some interactive loop circuits between capsaicin and miR-449a.

\section{Discussion}

Capsaicin, the pungent ingredient of natural capsicum, has been reported to prevent $\mathrm{PCa}$ growth and improve strategies of PCa therapy in previous studies. Ceramide accumulation, JNK activation and induction of the endoplasmic reticulum stress protein GADD153/CHOP were found to be involved in the mechanisms of apoptosis caused by capsaicin treatment $(9,18)$. Mori et al found that capsaicin inhibited TNF- $\alpha$-stimulated degradation of $\mathrm{I} \kappa \mathrm{B} \alpha$ and then inactivated $\mathrm{NF}-\kappa \mathrm{B}$ by preventing its nuclear migration in PC-3 cells (19). In addition, capsaicin also functioned as a radio-sensitizing agent through the inhibition of NF- $\kappa \mathrm{B}$ signaling in an athymic mouse model of PCa (20). In the present study, we verified the antitumor effect of capsaicin on AR-positive PCa cells. Capsaicin treatment at the indicated concentrations decreased cell viability in a dose-dependent manner in the C4-2 and LNCaP cells (Fig. 1). The cell cycle is a series of tightly ordered steps regulated by different checkpoints which detect extracellular growth signals, protein synthesis and DNA integrity (21). Aberrant cell proliferation characteristic of cancer cells is due to the disorder of the cell cycle. Flow cytometric analysis showed that capsaicin treatment $(100 \mu \mathrm{M})$ resulted in $\mathrm{G}_{0} / \mathrm{G}_{1}$ phase arrest, but had little impact on cell apoptosis (Fig. 2). Therefore, we confirmed that capsaicin resulted in growth arrest through arrest of cell cycle progression, consistent with the findings of other researchers.

Currently, AR remains the most important therapeutic target for PCa treatment. Anti-androgen drugs, such as casodex, enzalutamide and flutamide, have been used to cure PCa. However, clinical therapies that target the androgen-dependent AR signaling axis eventually fail due to the fact that AR is activated by other stimuli or signaling pathways. Thus, therapeutic strategies which promotes AR degradation in castration-resistant PCa have attracted the research interest of scientists. Researchers have indicated that promoting the degradation of AR protein shows better antitumor efficacy. Previous studies demonstrated that ASC-J9, a novel drug derived from curcumin, enhanced the degradation of AR to suppress the growth of castration-resistant PCa cells (22-24). 
A

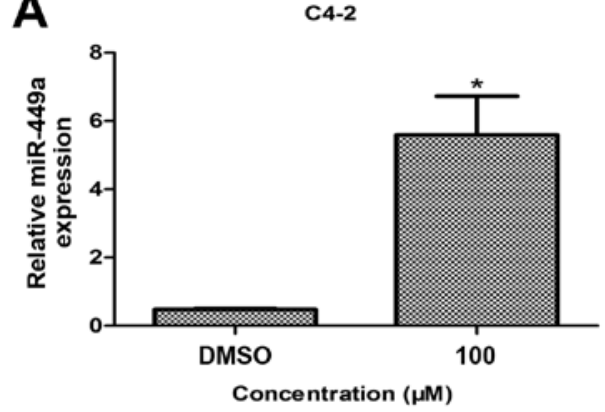

B



C



D

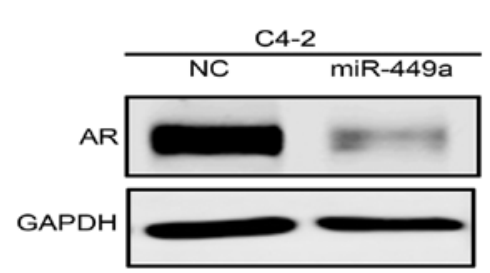

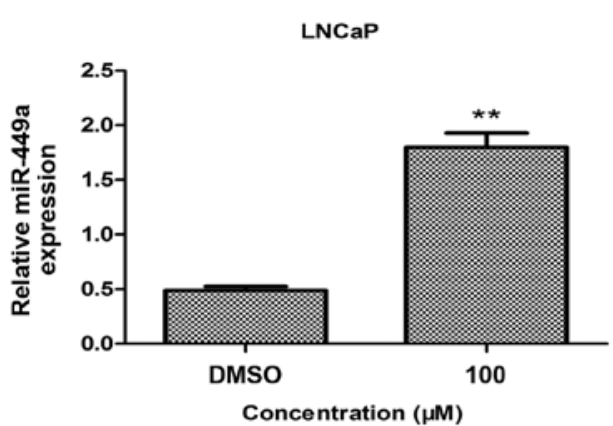

LNCaP
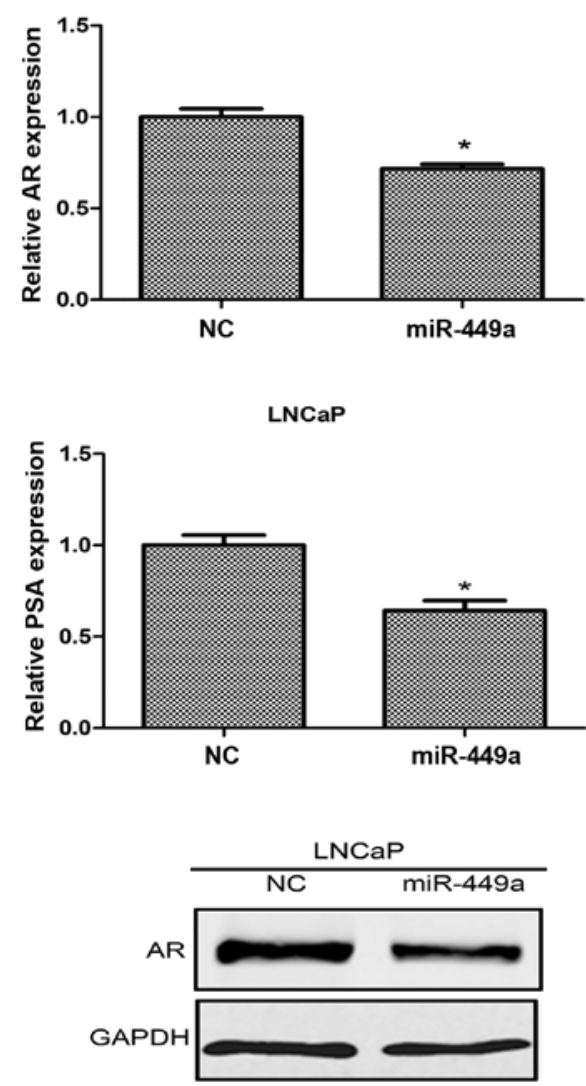

Figure 4. Restoration of miR-449a expression induced by capsaicin mediates a decrease in AR protein and inactivation of AR signaling. (A) Influence of capsaicin on the expression of miR-449a in the prostate cancer cells. (B and C) Overexpression of miR-449a by lentivirus inhibited AR and PSA mRNA expression. (D) Overexpression of miR-449a decreased the AR protein level. NC, negative control; miR-449a, cells transfected with the miR-449a lentivirus. * $\mathrm{P}<0.05$ and *** $\mathrm{P}<0.01$.

Scolit et al demonstrated that hsp90 function inhibitor, 17-allylamino-17-demethoxygeldanamycin (17-AAG) resulted in a marked reduction in AR degradation and inhibition of prostate tumor growth in mice (25). In the present study, we detected the influence of capsaicin on the AR protein level and its downstream target gene, PSA (Fig. 3). We found that capsaicin promoted AR protein degradation and inhibited AR activity in androgen-independent $\mathrm{PCa}$ cells and then inhibited proliferation of PCa cells. Our data indicated that capsaicin acts as a tumor suppressor though negative regulation of AR expression and activation.

Previous research has shown the roles of miRNAs as novel oncogenes or tumor-suppressor genes and their potential for PCa diagnosis, prognosis and therapy (10). The function of AR in $\mathrm{PCa}$ is related to expression of miRNAs. Interfering with AR mRNA translation directly or genes that may regulate AR are main mechanisms of miRNAs. For example, miR-let-7c was found to suppress AR expression and activity in human PCa cells via negative regulation of c-Myc activity (26). Epis et al demonstrated that miR-331-3p inhibited AR function and blocked AR signaling via interfering with ERBB-2 expression and AKT activity in PCa cells (27). In addition, a similar result was also discovered in PCa with overexpression of miR-448 (28). In the present study, we focused on miR-449a. As mentioned previously, miR-449a plays a role in inducing growth arrest in PCa cells. Östling et al conducted a systematic screening of 1129 miRNAs in a series of human PCa cell lines and quantified the changes in AR protein using a protein lysate microarray. Their data indicated that miR-449a regulated AR 3'UTR and decreased androgen-induced proliferation of PCa cells (29). Our data found that capsaicin treatment significantly increased the miR-449a level. Further experiments proved that 
A

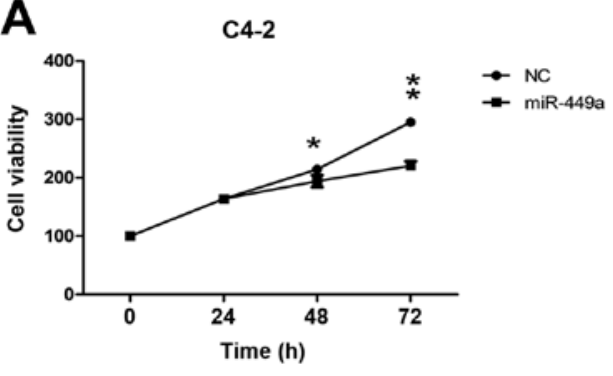

B
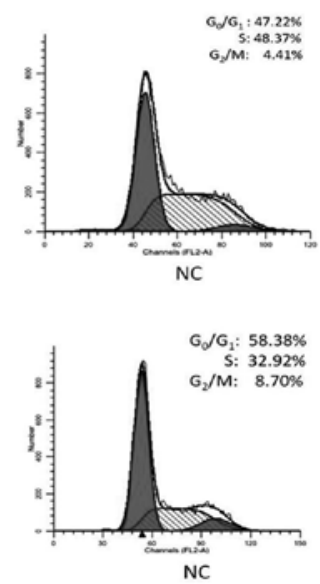

C




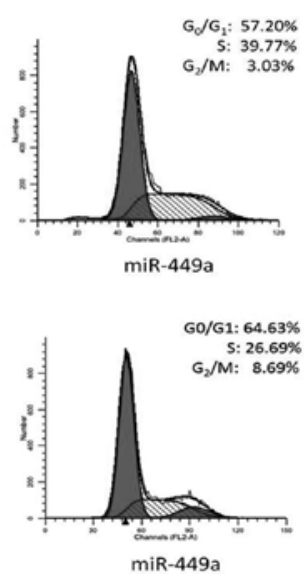

LNCaP



$\rightarrow \mathrm{NC}$

$\rightarrow$ miR-449a

Figure 5. Overexpression of miR-449a inhibits prostate cancer proliferation and enhances the antitumor effect of capsaicin. (A) Effect of miR-449a on prostate cancer cell proliferation, as detected by MTT assay. (B) miR-449a induces $\mathrm{G}_{0} / \mathrm{G}_{1}$ arrest in prostate cancer cells, as detected by flow cytometry. (C) Overexpression of miR-449a facilitates the growth inhibition mediated by capsaicin treatment in the prostate cancer cells. NC, negative control; miR-449a, cells transfected with the miR-449a lentivirus. ${ }^{*} \mathrm{P}<0.05$ and ${ }^{* *} \mathrm{P}<0.01$.



Figure 6. Summary of the mechanisms involved in the capsaicin-mediated effects on prostate cancer cells. Capsaicin induces upregulation of miR-449a in prostate cancer cells and then restoration of miR-449a interferes with the expression of AR mRNA. Synthesis of AR protein is inhibited, while AR degradation is enhanced. Thus, classic AR signaling is inactivated consequently leading to growth inhibition and cell cycle arrest of prostate cancer cells. 
an increased level of miR-449a downregulated AR protein and decreased the level of PSA (Fig. 4). Therefore, we demonstrated that restoration of miR-449a by capsaicin treatment mediated the degradation of AR and inhibition of AR activity. Then, we discovered that an increased level of miR-449a prevented proliferation and arrested the cell cycle in PCa cells. In fact, capsaicin has been indicated to interact with miRNAs. Triggering pain signaling by acute noxious stimulation of capsaicin increased the expression of miR-1 and miR-16 in DRG cells (13). Chakraborty et al found that increased miR-34a expression by capsaicin decreased the survival advantage and enhanced Bax-dependent apoptosis in non-small cell lung cancers (16). Kaymaz et al proved that capsaicin suppressed the growth of chronic myelogenous leukemia cells by decreasing expression of miR-520a-5p which was shown as a probable oncogene (17). They also found that inhibition of miR520-5p enhanced the antitumor effect of capsaicin. In the present study, overexpression of miR-449a, a tumor suppressor, facilitated the growth inhibition of capsaicin treatment (Fig. 5). However, the mechanisms involved with capsaicin induced restoration of miR-449a needs further study.

In conclusion, the results from our experiments clearly demonstrated that capsaicin degrades AR protein and inactivates AR function leading to decreased growth in AR-positive PCa cells. Then, we discovered that restoration of miR-449a by capsaicin mediated the degradation of AR and inactivation of AR signaling (Fig. 6). The present study indicated that capsaicin, a biomolecule extracted from natural capsicum, may be used as a novel drug targeting AR signaling in PCa treatment.

\section{Acknowledgements}

This study was supported by the National Natural Science Foundation of China (grant no. 81072107, 81472679).

\section{References}

1. Siegel R, Ma J, Zou Z and Jemal A: Cancer statistics, 2014. CA Cancer J Clin 64: 9-29, 2014.

2. Scher HI, Beer TM, Higano CS, Anand A, Taplin ME, Efstathiou E, Rathkopf D, Shelkey J, Yu EY, Alumkal J, et al; Prostate Cancer Foundation/Department of Defense Prostate Cancer Clinical Trials Consortium: Antitumour activity of MDV3100 in castration-resistant prostate cancer: A phase 1-2 study. Lancet 375: 1437-1446, 2010.

3. Culig Z, Klocker H, Bartsch G and Hobisch A: Androgen receptors in prostate cancer. Endocr Relat Cancer 9: 155-170, 2002.

4. Heinlein CA and Chang C: Androgen receptor in prostate cancer. Endocr Rev 25: 276-308, 2004.

5. Chen Y, Clegg NJ and Scher HI: Anti-androgens and androgendepleting therapies in prostate cancer: New agents for an established target. Lancet Oncol 10: 981-991, 2009.

6. Montgomery RB, Mostaghel EA, Vessella R, Hess DL, Kalhorn TF, Higano CS, True LD and Nelson PS: Maintenance of intratumoral androgens in metastatic prostate cancer: A mechanism for castration-resistant tumor growth. Cancer Res 68: 4447-4454, 2008.

7. Watson PA, Chen YF, Balbas MD, Wongvipat J, Socci ND, Viale A, Kim K and Sawyers CL: Constitutively active androgen receptor splice variants expressed in castration-resistant prostate cancer require full-length androgen receptor. Proc Natl Acad Sci USA 107: 16759-16765, 2010

8. Díaz-Laviada I and Rodriguez-Henche N: The potential antitumor effects of capsaicin. Progr Drug Res 68: 181-208, 2014

9. Sánchez AM, Malagarie-Cazenave S, Olea N, Vara D, Chiloeches A and Díaz-Laviada I: Apoptosis induced by capsaicin in prostate PC-3 cells involves ceramide accumulation, neutral sphingomyelinase, and JNK activation. Apoptosis 12: 2013-2024, 2007.
10. Jansson MD and Lund AH: MicroRNA and cancer. Mol Oncol 6: 590-610, 2012.

11. Noonan EJ, Place RF, Basak S, Pookot D and Li LC: miR-449a causes $\mathrm{Rb}$-dependent cell cycle arrest and senescence in prostate cancer cells. Oncotarget 1: 349-358, 2010.

12. Noonan EJ, Place RF, Pookot D, Basak S, Whitson JM, Hirata H, Giardina C and Dahiya R: miR-449a targets HDAC-1 and induces growth arrest in prostate cancer. Oncogene 28: 1714-1724, 2009.

13. Kusuda R, Cadetti F, Ravanelli MI, Sousa TA, Zanon S, De Lucca FL and Lucas G: Differential expression of microRNAs in mouse pain models. Mol Pain 7: 17, 2011.

14. Gill R, Kuriakose R, Gertz ZM, Salloum FN, Xi L and Kukreja RC: Remote ischemic preconditioning for myocardial protection: Update on mechanisms and clinical relevance. Mol Cell Biochem 402: 41-49, 2015.

15. Jankovic B, Loblaw DA and Nam R: Capsaicin may slow PSA doubling time: Case report and literature review. Can Urol Assoc J 4: E9-E11, 2010.

16. Chakraborty S, Mazumdar M, Mukherjee S, Bhattacharjee $P$, Adhikary A, Manna A, Chakraborty S, Khan P, Sen A and Das T: Restoration of $\mathrm{p} 53 / \mathrm{miR}-34 \mathrm{a}$ regulatory axis decreases survival advantage and ensures Bax-dependent apoptosis of non-small cell lung carcinoma cells. FEBS Lett 588: 549-559, 2014.

17. Kaymaz BT, Cetintaş Kaymaz VB, Aktan C and Kosova B: MicroRNA-520a-5p displays a therapeutic effect upon chronic myelogenous leukemia cells by targeting STAT3 and enhances the anticarcinogenic role of capsaicin. Tumour Biol 35: 8733-8742, 2014.

18. Sánchez AM, Martínez-Botas J, Malagarie-Cazenave S, Olea N, Vara D, Lasunción MA and Díaz-Laviada I: Induction of the endoplasmic reticulum stress protein GADD153/CHOP by capsaicin in prostate PC-3 cells: A microarray study. Biochem Biophys Res Commun 372: 785-791, 2008.

19. Mori A, Lehmann S, O'Kelly J, Kumagai T, Desmond JC, Pervan M, McBride WH, Kizaki M and Koeffler HP: Capsaicin, a component of red peppers, inhibits the growth of androgenindependent, p53 mutant prostate cancer cells. Cancer Res 66: 3222-3229, 2006.

20. Venier NA, Colquhoun AJ, Sasaki H, Kiss A, Sugar L, Adomat H, Fleshner NE, Klotz LH and Venkateswaran V: Capsaicin: A novel radio-sensitizing agent for prostate cancer. Prostate 75: 113-125, 2015.

21. Park M-T and Lee S-J: Cell cycle and cancer. J Biochem Mol Biol 36: 60-65, 2003.

22. Yamashita S, Lai KP, Chuang KL, Xu D, Miyamoto H, Tochigi T, Pang ST, Li L, Arai Y, Kung HJ, et al: ASC-J9 suppresses castrationresistant prostate cancer growth through degradation of full-length and splice variant androgen receptors. Neoplasia 14: 74-83, 2012.

23. Lin TH, Lee SO, Niu Y, Xu D, Liang L, Li L, Yeh SD, Fujimoto N, Yeh S and Chang C: Differential androgen deprivation therapies with anti-androgens casodex/bicalutamide or MDV3100/Enzalutamide versus anti-androgen receptor ASC-J9(R) lead to promotion versus suppression of prostate cancer metastasis. J Biol Chem 288: 19359-19369, 2013.

24. Lin TH, Izumi K, Lee SO, Lin WJ, Yeh S and Chang C: Anti-androgen receptor ASC-J9 versus anti-androgens MDV3100 (Enzalutamide) or Casodex (Bicalutamide) leads to opposite effects on prostate cancer metastasis via differential modulation of macrophage infiltration and STAT3-CCL2 signaling. Cell Death Dis 4: e764, 2013.

25. Solit DB, Zheng FF, Drobnjak M, Münster PN, Higgins B, Verbel D, Heller G, Tong W, Cordon-Cardo C, Agus DB, et al: 17-Allylamino-17-demethoxygeldanamycin induces the degradation of androgen receptor and HER-2/neu and inhibits the growth of prostate cancer xenografts. Clin Cancer Res 8: 986-993, 2002.

26. Nadiminty N, Tummala R, Lou W, Zhu Y, Zhang J, Chen X, eVere White RW, Kung HJ, Evans CP and Gao AC: MicroRNA let-7c suppresses androgen receptor expression and activity via regulation of Myc expression in prostate cancer cells. J Biol Chem 287: 1527-1537, 2012.

27. Epis MR, Giles KM, Barker A, Kendrick TS and Leedman PJ: miR-331-3p regulates ERBB-2 expression and androgen receptor signaling in prostate cancer. J Biol Chem 284: 24696-24704, 2009.

28. Sikand K, Slaibi JE, Singh R, Slane SD and Shukla GC: miR $488^{*}$ inhibits androgen receptor expression in prostate carcinoma cells. Int J Cancer 129: 810-819, 2011.

29. Östling P, Leivonen SK, Aakula A, Kohonen P, Mäkelä R, Hagman Z, Edsjö A, Kangaspeska S, Edgren H, Nicorici D, et al: Systematic analysis of microRNAs targeting the androgen receptor in prostate cancer cells. Cancer Res 71: 1956-1967, 2011. 